Original research article

\title{
Conjugate ecological restoration approach with a case study in Mentougou district, Beijing
}

\author{
Jiasheng Jin, Rusong Wang *, Feng Li, Jinlou Huang, Chuanbin Zhou, Haitao Zhang, Wenrui Yang \\ State Key Laboratory of Urban and Regional Ecology, Research Center for Eco-environmental Sciences, Chinese Academy of Sciences, No. 18, Shuangqing Road, \\ Haidian District, Beijing 100085, PR China
}

\section{A R T I C L E I N F O}

\section{Article history:}

Received 7 October 2010

Received in revised form 7 January 2011

Accepted 8 January 2011

Available online 25 February 2011

\section{Keywords:}

Conjugate ecological restoration plan

Evaluation system

Full Permutation Polygon Synthetic

Indicator Method

\begin{abstract}
A B S T R A C T
Ecological restoration is a comprehensive engineering field that involves multidisciplinary and multisectoral efforts. More and more research works have been focused on ecological restoration since the 1980s. However, until now, most studies pay attention mainly on ecological technology, ecological policy, restoration of some certain ecosystem, and so on. There are few studies regarding the restoration plan of regional or the entire ecosystem. The objects of present research studies are mainly natural ecosystem; however, ecosystem is a complex system that encompasses natural, economic, and social sectors. Human society has great intimidation on nature, and if the degenerate social and economical systems do not get restored, the vicious cycle of degeneration will continue and the effects of natural ecosystem restoration cannot possibly be guaranteed.

In this article, the author puts forward conjugate ecological restoration based on theories of complex ecosystem and restoration ecology. The connotation is scientifically described and an evaluation system is established. Natural, economic, and social ecosystem restoration plans are presented and made based on the comprehensive evaluation. Conjugate ecological restoration plan in Mentougou district, Beijing, is taken as a case study. The plan includes three parts: nature, economy, and society. Moreover, ecological restoration technologies and demonstration projects are designed for different types of degradation.

The author modifies the Full Permutation Polygon Synthetic Indicator Method and uses it in the comprehensive evaluation. Compared with the original method, the weight parameter is added into the evaluation system, which makes the method more scientific.
\end{abstract}

(c) 2011 Elsevier B.V. All rights reserved.

\section{Introduction}

The history of ecological restoration research dates back to the 1930s. Cairns made a systematic research on ecological restoration at around 1980 in his book The Recovery Process in Damaged Ecosystems and from then on restoration ecology became a branch of ecology. There are many concepts related to ecological restoration in research and practice other than just restoration; these include rehabilitation, reconstruction, renewal, reclamation, and so on. Although there are some slight differences among these concepts, they all mean recovery and development, that is, recover the damaged ecosystem so that it can develop and service human beings sustainably.

Ecological restoration is the exact opposite of ecological destruction, which means that the structure, function, and relationship of ecosystem suffer damages. Thus the main task of ecological restoration is to recover the ecosystem so that it has a

\footnotetext{
* Corresponding author. Tel.: +8610 62843807; fax: +86 1062843807 .

E-mail address: wangrs@rcees.ac.cn (R. Wang).
}

reasonable structure, efficient function, and harmonious relationship. Jordan posits that ecological restoration means recovering the ecosystem to the original or historical (natural or not natural) level (Jordan, 1994). Cairns considers ecological restoration as the recovery of the structure and function of ecosystem to the state when it has not been disturbed by its surroundings (Cairns, 1995). The US Natural Resource Council defines ecological restoration as the process that returns the ecosystem to, or close to, its historic trajectory (Peng, 2003). The Society for Ecological Restoration puts forward three definitions for ecological restoration in 1994 and 1995 , and the final definition is that ecological restoration is the process of assisting in the recovery of an ecosystem that has been degraded, damaged, or destroyed (Jackson et al., 1995). These definitions mostly emphasize on the recovery of the natural ecosystem through various techniques and measures to allow it to return to its former state.

An international conference with the theme the recovery of damaged ecosystem' was held at University of Virginia in March 1973. It focused on the ecological issues of recovery and reconstruction of damaged ecosystems. In 1985, Aber and Jordan put forward the scientific terminology 'restoration ecology'. 
Restoration ecology has been gaining rapid development since the 1980s and many international organizations and countries have developed research in this field. The central issue of the Man and Biosphere Program (MAB, the United Nations Educational, Scientific and Cultural Organization) is to study the relationship between nature and humans especially the impact of human activities on the ecosystem through ecological methods. The Sustainable Biosphere Initiative (USA) sets restoration ecology as its main research content. Furthermore, many great international programs include research on restoration ecology, including the International Geosphere-Biosphere Programme (IGBP), International Human Dimensions Programme on Global Environment Change (IHDP), Global Environment Monitoring System (GEMS), and so on. The Society for Ecological Restoration (SER) International has held 17 International Conferences on Ecological Restoration and has greatly promoted the development of restoration ecology.

Ecological restoration has become a research hotspot of ecology and has achieved special attention from the ecology academia. Recently, many studies have been carried out and some of those are relatively active such as soil restoration (Zhou et al., 2007; Ravindran et al., 2007; Mitchell, 2008), forest restoration (Lamd, 1994; Maginnis and Jackson, 2002; Barrow et al., 2002), mine restoration (Hart et al., 1999; Jolanta, 2006; Majer et al., 2007), grassland restoration (Navarro et al., 2006; Willems, 2001), river restoration (Tennant, 1976; Poff et al., 1997; Boon et al., 2000), lake restoration (Sagehashi et al., 2001; Hupfer and Hilt, 2008; Gulati et al., 2008), wetland restoration (Selby, 2000; Sparks, 2001; Verhoeven et al., 2008; Dolinar et al., 2010), biodiversity protection(Cornelia et al., 2010), and so on (Patten, 2010).

The ecological restoration studies are mainly focused on restoration techniques or some ecosystem restoration programs at present. Very few research works, however, are concerned with regional ecological restoration plan (Li and Wang, 2007). Many problems are still unresolved, including how to carry out ecological restoration with measured strokes in a region and how to apply ecological restoration technologies. In cases where there are ecological plans, most of such plans are made based on urban planning methods or the subjective intentions of decision makers. The restoration object is primarily the natural ecosystem, rather than social and economic ecosystems, which have great influence on natural ecosystems (Zurlini et al., 2006), thus the effects of restoration are not guaranteed. In addition, there are many research attempts regarding the standards of restored ecosystem, however, there has not been a unified standard; most studies try to compare an ecosystem after restoration with an undisturbed ecosystem, and their evaluation objects include abundance and behavior of key species, rebuilding of key ecological processes, recovery of abiological characters as hydrological process, and so on (Cairns, 1977; Rapport et al., 1998; Ren et al., 2000).

\section{Connotation of conjugate ecological restoration}

Ecology is the study of the relationship between organisms and environment (Haeckel, 1866). As early as the 1980s, Ma and Wang summarized ancient Chinese practices of natural protection, ecological agriculture, and ecological engineering and pointed out that human society is a social-economic-natural complex ecosystem, which is led by human activities, and that it depends on the natural environment, takes the resource flows as its lifeline and social institution as its meridian (Ma and Wang, 1984; Wang, 1988). The essence of sustainable development is the coordinated development of relationship between humans and their inhabitation, labor, material production, and socialcultural environments.

Ecological restoration means the restoration of the structure, processes, and functions of ecosystems, and shows the restoration of the ecosystem service functions in a macroscopical view. The ecosystem service functions are characterized by double facets and double directions: the positive factors provide humans with air conservation and biomass production, among other things. On the contrary, the negative factors cause natural damages and disasters. Ecosystems provide humans with service functions, while humans also provide ecosystems the social services of ecological constructions and improvements. When we assess the effects of ecological remediation, a double-win mechanism between human society and natural ecosystem is important; it means that ecosystem service functions could evolve, and the double facets and directions of eco-services could bring cost-benefit balance.

Conjugation means a relationship where both factors are opposite but complementary and maintain coordinate symbiosis with each other. When the conjugation theory is applied to ecology, it refers to the balance between social and ecological services, economic and natural productions, coordination of space and time linkage, and harmony between physical and spiritual states. The key factors of ecological conjugation include: (1) adjusting the natural processes of water, soil, air, energy biology, and geochemical circulation; (2) adjusting the primary economic processes of production, circulation, consumption, restoration, regulation, and control; (3) adjusting the social processes of technology, institution, and culture; (4) adjusting the coupling relationship among natural economic and social processes in the scale of time, space, quantity, structure, and order; (5) promoting the technical system of ecological planning, ecological engineering,
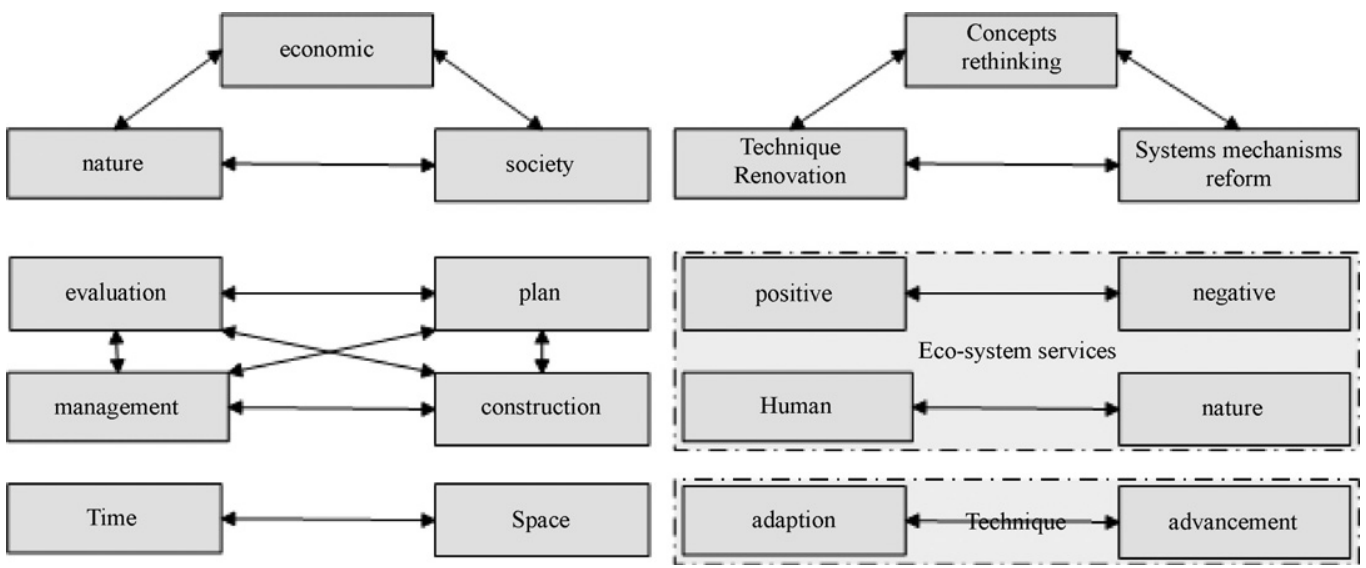

Fig. 1. Conjugate relationships in ecological restoration. 


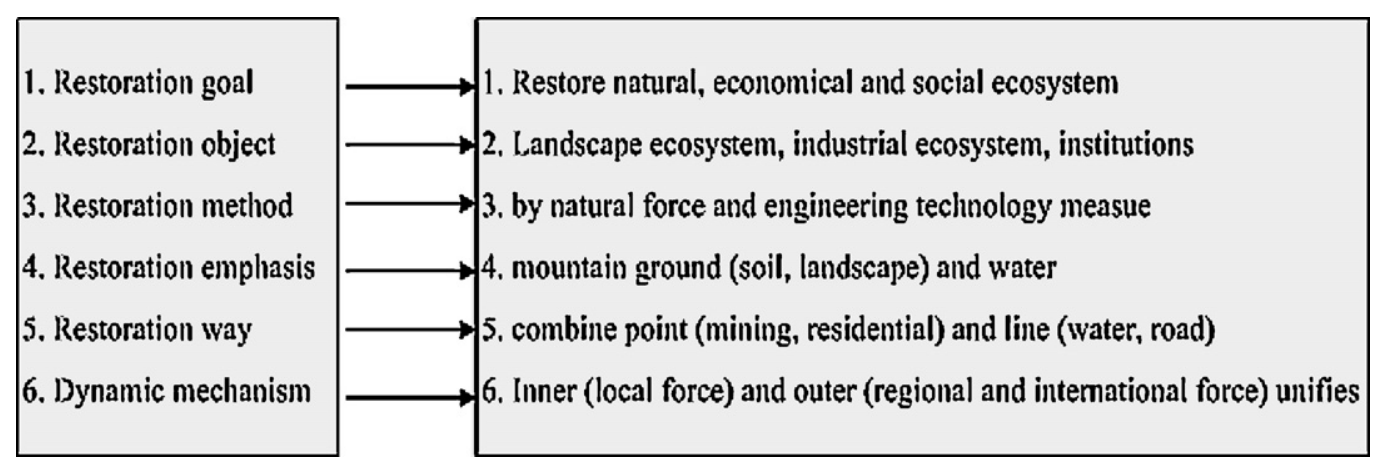

Fig. 2. Connotation of conjugate eco-restoration.

and ecological management in the bases of integer, cooperation, circulation, and self-sustainability. These key factors are applied to realize the high-speed social economic development premised on the conservation of the activity of nature. Thus ecological restoration includes three factors, namely, natural ecology, economic ecology, and cultural ecology. The basic objectives start from the rethinking of concepts; reform of institutions and renovation of technologies; restoring, conserving, and strengthening of social, economic, and natural ecology services; promoting the co-evolution of nature and humans; and guaranteeing the maximum protection and development of regional ecology security, urban and country construction, industries and inhabitants' somatopsychic health. The conjugate relationships in ecological restoration are shown in Fig. 1.

Thus, conjugate ecological restoration consists of the following: (1) restoration by natural force and human-induced restoration; (2) landscape restoration and industry restoration; (3) green (vegetation and forest), blue (rivers, lakes, and other water) space restoration, red (construction lands), and brown (landfills, traffic lands, wastelands, etc.) space restoration; (4) mountain ground restoration and water root restoration; (5) industrial, mining, and residential point restoration as well as water and road network restoration; (6) restoration led by government for public welfare and restoration by enterprises as their feedback; (7) internal selfadjusting restoration and restoration from external compensation; (8) space-order restoration and time-order restoration. (See in Fig. 2.)

\section{Approach for conjugate ecological restoration plan}

Conjugate ecological restoration plan has three aspects: natural ecological restoration, economical ecological restoration, and social ecological restoration. The restoration of every subsystem impacts other subsystems

\subsection{Indicator system}

An indicator system is an aggregation of indicators that follow scientific, feasible, independent, integrated, succinct, hierarchical and stable rules, among others.

According to the scale and connotation of conjugate ecological restoration previously mentioned, the indicator system in this research has four layers, considering mainly the development and intimidation aspects, and containing indicators of three subsystems, namely, nature, economy, and society. Indicators are selected by experts and local officials using the game process method. If more than half of the experts consider the indicator of no importance, the indicator would not be selected. Indicators that have much relativity will be unified or the easily obtained indicators will be selected. Indicators considered by $80 \%$ of the experts would be selected after three turns of consultation with them. The finally constituted indicators are shown in Table 1.

\subsection{Evaluation method}

\subsubsection{Study unit selection}

Using the grid method, the study area will be divided into net grids and the average value of each indicator in each grid will be calculated using the data processing function of Arcgis9.2 and Matlab7.1. The net grid (study unit) can be a regular square or some other shapes depending on the management preference, e.g., watershed grid. The size and quantity of the net grid will be decided by the scale of study area.

Table 1

Conjugate Eco-restoration Indicator System (CERIS).

\begin{tabular}{|c|c|c|c|}
\hline First-layer indicator & Second-layer indicator & Third-layer indicator & Fourth-layer indicator \\
\hline \multirow{16}{*}{$\begin{array}{l}\text { Indicator of ecological } \\
\text { restoration importance }\end{array}$} & \multirow[t]{10}{*}{ Development indicators } & \multirow[t]{4}{*}{ Natural services } & NDVI indicator \\
\hline & & & Nutrition concentration in soil \\
\hline & & & Quantity of water resource \\
\hline & & & Quantity of minerals \\
\hline & & \multirow[t]{6}{*}{ Economical and social services } & Transportation accessibility \\
\hline & & & Location advantage \\
\hline & & & Integrity of infrastructure \\
\hline & & & Degree of economy development \\
\hline & & & Degree of resource exploitation \\
\hline & & & Density of population \\
\hline & \multirow[t]{6}{*}{ Intimidation indicators } & \multirow[t]{3}{*}{ Natural intimidation } & Degree of vegetation degradation \\
\hline & & & Frequency of geologic hazard \\
\hline & & & Degree of soil and water loss \\
\hline & & \multirow{3}{*}{$\begin{array}{l}\text { Economical and } \\
\text { social intimidation }\end{array}$} & Degree of main economic activity " 1 " destruction \\
\hline & & & \\
\hline & & & Degree of main economic activity " $n$ " destruction \\
\hline
\end{tabular}




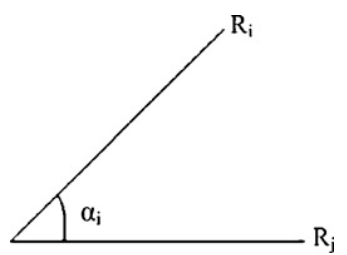

Fig. 3. An indicator and its weight angle.

\subsubsection{Indicator synthesis}

$\mathrm{Wu}$ et al. developed the Full Permutation Polygon Synthetic Indicator Method (FPPSI) to synthesize indicators and evaluate the comprehensive level (Wu et al., 2005; Li et al., 2007; Cheng et al., 2007; Wang and Bian, 2007). When used in evaluation, the FPPSI method has the following advantages over other methods: (1) it requires analysts to set upper and lower limits and critical values (by referring to correlative thresholds); all indicators form a vector $F\left(R_{1}, R_{2}, \ldots, R_{n}\right)$. By doing this, we can directly see the level of each indicator and the distance between the present level and the critical, upper, and lower level; (2) the vector $F\left(R_{1}, R_{2}, \ldots, R_{n}\right)=R$ is the comprehensive indicator combined by all indicators and reflect the overall level; (3) the approach provides not only a geometrically intuitive visualization of the status of each indicator, but also precise algebraic values. It provides both static indicators and the ability to portray dynamic temporal trends; (4) the FPPSI method alters the traditional additive approach to combining indicators by using a multidimensional approach that better reflects the integrative system principle that the whole is more than the sum of its parts.

This approach is imperfect because it takes the equal weights when synthesizing the lower layer indicators. In this article, the author ameliorates the method by adding a parameter as the weight of an indicator and uses the Improved Permutation Polygon Synthetic Indicator Method (IFPPSI) to evaluate the importance of ecological restoration.
The weight of indicator $R_{i}$ is $\omega_{i}$, corresponding to angle $\alpha_{i}$, and the change in $\alpha_{i}$ reflects the change of the weight of $R_{i}\left(\omega_{i}\right)$ (Fig. 3) The following requirements must be met:

(1) $\omega_{i}=\frac{\alpha_{i}}{2 \pi}$

(2) $\alpha_{i}<\pi / 2$, because under this condition, $\sin \alpha_{i}$ is an increasing function and the area of the triangle that contains $R_{i}$ and $\alpha_{i}$ has the same monotonicity with $\omega_{i}$. That is, when an indicator has a larger weight than before (the value of $R_{i}$ is unchanged), it has a larger area.

Thus,

(1) $n \geq 5$, ' $n$ ' means the number of the indicators;

(2) $\omega_{i} \leq 0.25, i=1,2,3, \ldots, n$.

3.2.2.1. Standardization process of indicators. The standardization process can be described as follows:

$F(x)=a \frac{x+b}{x+c} \quad a \neq 0, \quad x \geq 0$

where $F(x)$ meets the following conditions:

$\left.F(x)\right|_{x=L}=-1,\left.\quad F(x)\right|_{x=T}=0,\left.\quad F(x)\right|_{x=U}=1$

where $U, L$, and $T$ represent the upper limit, the lower limit, and the threshold for parameter $x$ respectively. Thus:

$F(x)=\frac{(U-L)(x-T)}{(U+L-2 T) x+U T+L T-2 L U}$

When $x \in[L, U], F(x)$ has the following characters:

(1) $F(x)$ has significance, that is, it has no singular value in its domain;

(2) $F^{\prime}(x) \geq 0$

(3) When $x \in(T, U), F^{\prime \prime}(x)>0$;

(4) When $x \in[L, T], F^{\prime \prime}(x)<0$.

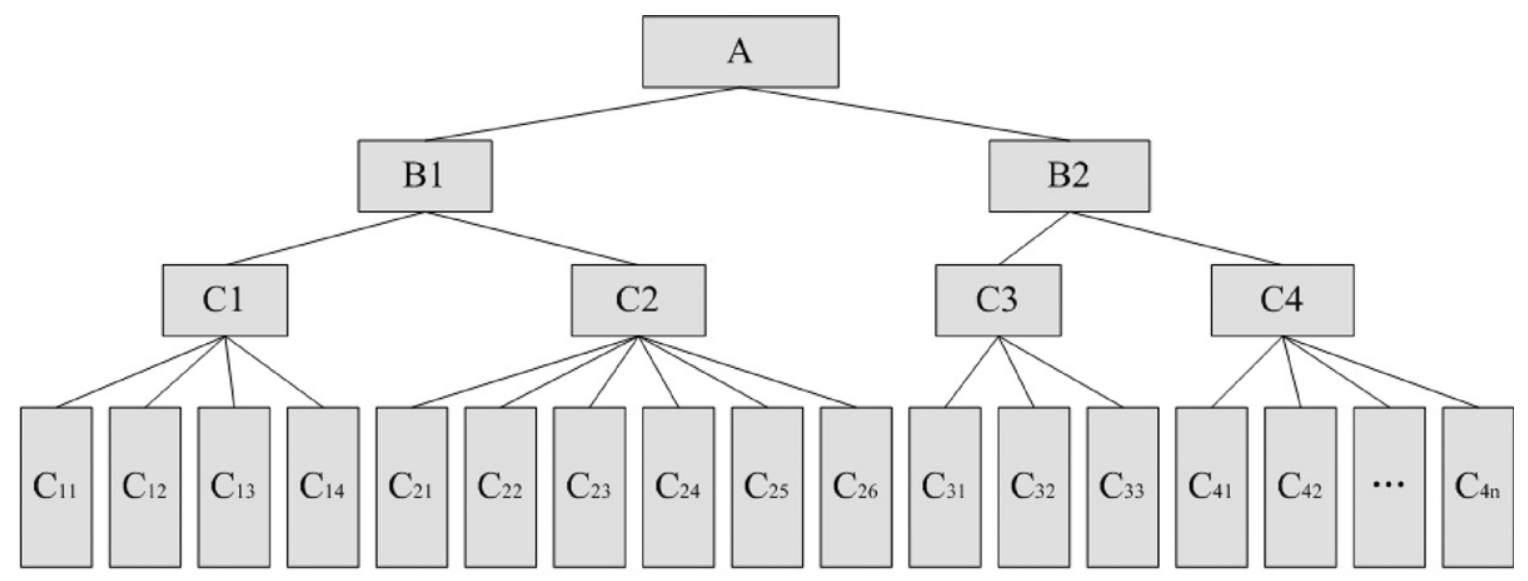

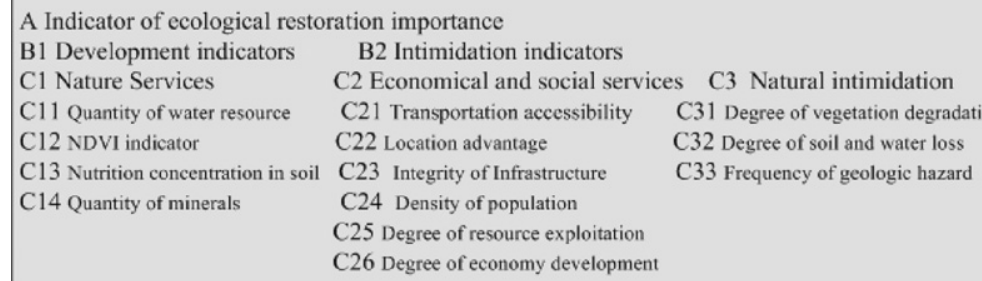
C3 Natural intimidation

C4 Economical and social intimidiation C31 Degree of vegetation degradation C41 Degree of main economic activity "1" destruction C32 Degree of soil and water loss C42 Degree of main economic activity "2" destruction C33 Frequency of geologic hazard C4n Degree of main economic activity " $n$ " destruction

Fig. 4. Hierarchical structure of CERIS. 


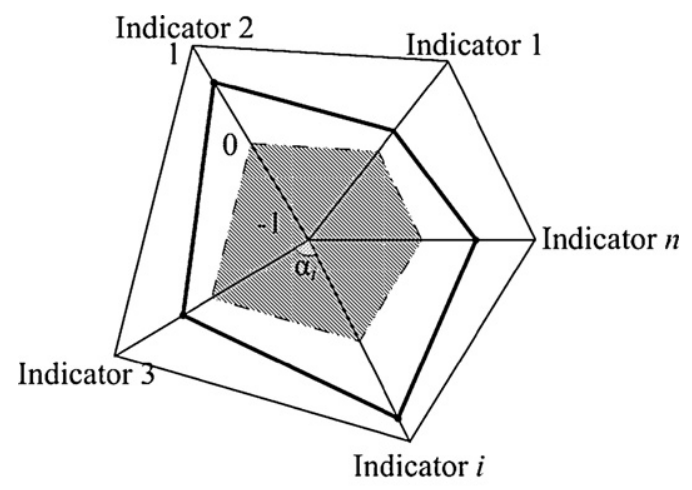

Evaluation result

Fig. 5. Improved Full Permutation Polygon Synthetic Indicator Method (IFPPSI).

The equation can then be standardized for each indicator:

$R_{i}=\frac{\left(U_{i}-L_{i}\right)\left(x_{i}-T_{i}\right)}{\left(U_{i}+L_{i}-2 T_{i}\right) x_{i}+U_{i} T_{i}+L T_{i}-2 L_{i} U_{i}}$

An outer regular $n$-sided polygon can be formed by $n$ indicators, where $n$ vertices represent the instance of $R_{i}=1$; the central point represents $R_{i}=-1$; and the radius from each vertex to the central point represents the value of the corresponding standardized indicator. An inner polygon that lies midway between the outer polygon and the center of the polygon represents the threshold values of the indicators, where $R_{i}=0\left(x_{i}=T\right)$. Inside the inner polygon, the values of the standardized indicators are less than their thresholds and are negative; outside the inner polygon, the values are greater than their threshold values and are positive (Fig. 5).

3.2.2.2. Weight of indicator. The weight of each indicator is calculated by consulting several experts through the group decision method based on the Analytic Hierarchy Process (AHP). The hierarchical structure of conjugate ecological restoration indicator system (CERIS) is then constructed (Fig. 4). Then, 3-5 experts are consulted on the importance of each indicator in the same layer, and matrixes are built and the weight of each indicator will be calculated.

3.2.2.3. Indication integration. The $n$ indicators can form $(n-1)$ ! different polygons containing $n$ ! triangles; in all these triangles, the number of different triangles is $n(n-1)$, and the total area of all these different triangles can be calculated as follows:

$S_{\Delta}=\frac{1}{2} \sum_{i \neq j}^{i, j}\left(R_{i}+1\right)\left(R_{j}+1\right) \sin \alpha_{i}$

where $R_{i}$ represents indicator $i$, and $\left(R_{i}+1\right)$ represents the distance from the endpoint of indicator $i$ to the central point. The standardization interval is $[-1,+1]$.

Thus, the sum of $(n-1)$ ! areas of the polygons is:

$S_{t}=\frac{n !}{n(n-1)} \frac{1}{2} \sum_{i \neq j}^{i, j}\left(R_{i}+1\right)\left(R_{j}+1\right) \sin \alpha_{i}$

The areas of the $(n-1)$ ! regular outer polygons (with a side length equal to 2 units) can be calculated as:

$S_{s t}=(n-1) ! \times \frac{1}{2} \times 4 \times \sum_{i=1}^{n} \sin \alpha_{i}$

Thus, the value of IFPPSI is obtained by calculating the following ratio:

$R=\frac{S_{t}}{S_{s t}}=\frac{1}{4(n-1)} \frac{\sum_{i \neq j}^{i, j}\left(R_{i}+1\right)\left(R_{j}+1\right) \sin \alpha_{i}}{\sum_{i=1}^{n} \sin \alpha_{i}}$

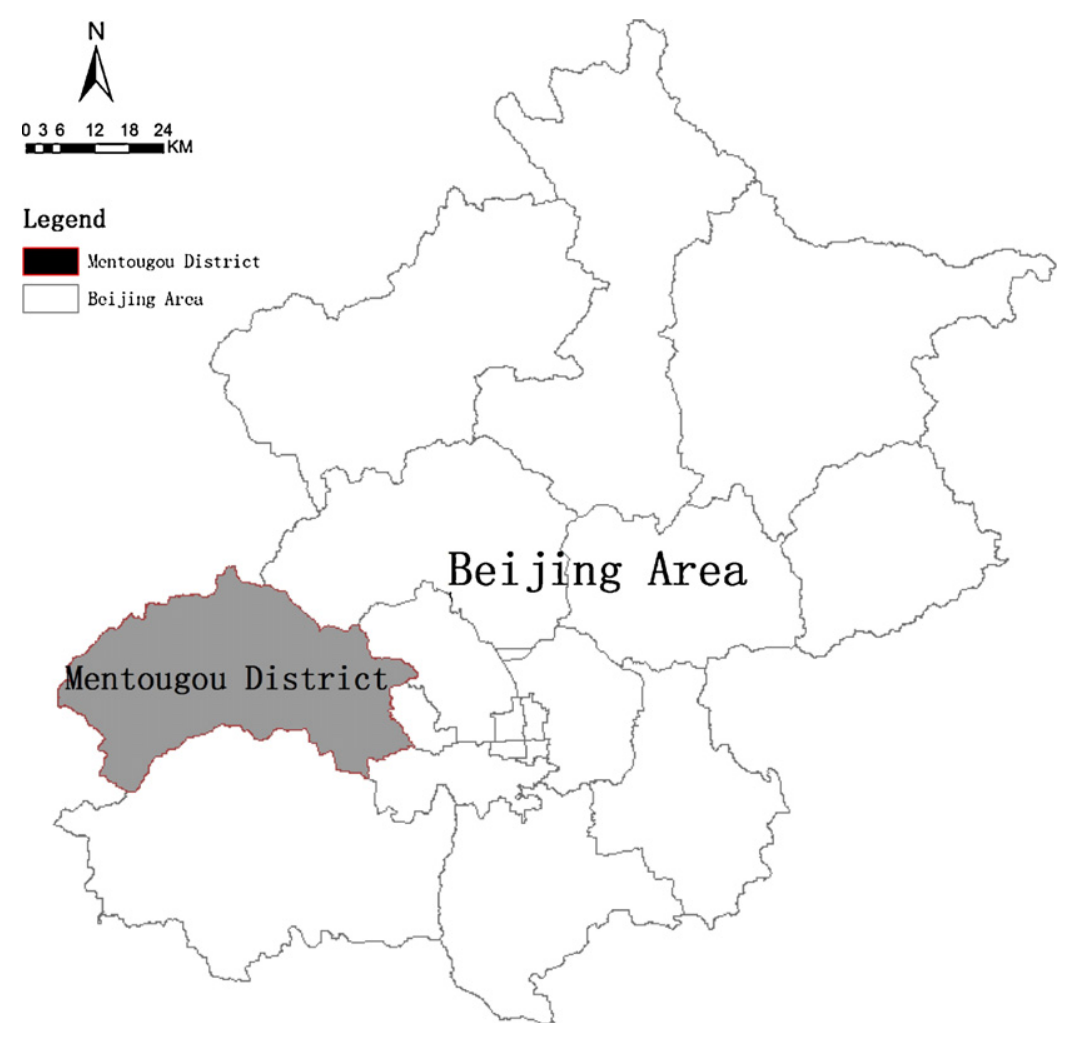

Fig. 6. Location of Mentougou district. 
where $R$ is the value of the synthetic indicator, which represents the sum of the values for all indicators at a lower layer in the hierarchy and can be standardized to account for the immediately higher layer in the hierarchy.

See the improved FPPSI in Fig. 5.

\section{Case study}

\subsection{Introduction of research area}

Mentougou is an ecological protective barrier of Beijing city located at the west terminal vertex of Chang'an street extension (Fig. 6). It has a superior position of water and wind of Beijing, and thus has excellent ecological qualification. It provides ecosystem services to Beijing including water conservation, soil conservation, air cleaning, climate regulation, leisure and healthcare, and others. It has abundant and highquality resources including organisms, geology, climate, culture, coal, sand, stone, and so on. It is the energy base of Beijing with its invaluable contribution to the energy and ecology security of Beijing. Currently, Mentougou has developed an extroverted arterial industry system which will lead to seriously destruct on ecosystem after a long time of exploitation of resources.

In order to maintain its function as ecological protective barrier, the development of Mentougou has been restricted. Longtime exploitation of resources has ravaged its geologic structure, destroyed the landscape and led to frequent geologic hazards, serious vegetation degradation, hydrology damage, soil and water loss. Slags and calxes from mining areas are the main sources of dust. Hazardous materials seep down to the groundwater during the rainy season and contaminate it. Mentougou has a serious ecological degradation at present.

\subsection{Data source}

The original data are mainly sourced from the Mentougou local government and others are sourced from remote sensing data.

\subsection{Data processing method}

\subsubsection{Study units}

In this study, we take a small watershed as the study unit for convenient restoration implementation and management. Using a digital elevation model (DEM) data, Mentougou is divided into 375

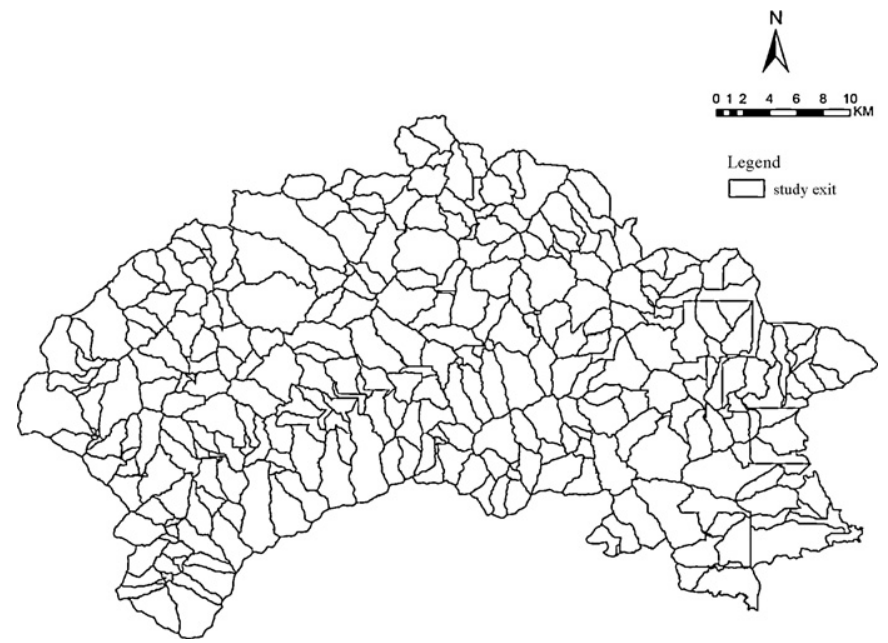

Fig. 7. Study units.
Table 2

Weights of indicators.

\begin{tabular}{lll}
\hline Indicator & Weight & Angle \\
\hline Quantity of minerals & 0.0188 & 0.1181 \\
Nutrition concentration in soil & 0.0486 & 0.3052 \\
NDVI indicator & 0.0690 & 0.4333 \\
Quantity of water resource & 0.0886 & 0.5564 \\
Degree of economy development & 0.0261 & 0.1639 \\
Degree of resource exploitation & 0.0390 & 0.2449 \\
Density of population & 0.0270 & 0.1696 \\
Integrity of infrastructure & 0.0460 & 0.2889 \\
Location advantage & 0.0377 & 0.2368 \\
Transportation accessibility & 0.0492 & 0.3090 \\
Frequency of geologic hazard & 0.0667 & 0.4189 \\
Degree of soil and water loss & 0.0814 & 0.5112 \\
Degree of vegetation degradation & 0.0994 & 0.6242 \\
Destruction degree of road project & 0.0641 & 0.4025 \\
Destruction degree of sand mining & 0.0641 & 0.4025 \\
Destruction degree of quarry & 0.0783 & 0.4917 \\
Destruction degree of coal mining & 0.0957 & 0.6010 \\
\hline
\end{tabular}

small watersheds by the watershed function of Swat2000 software (Fig. 7).

\subsubsection{Weights of indicators}

The weights of CERIS indicators are calculated by the AHP group decision process. See Table 2.

\subsection{Result}

\subsubsection{Indicator of ecological restoration importance}

Based on the method introduced above, indicators are synthesized and the ecological restoration importance indicator of each unit are calculated; the Arcgis9.0 software is then used to classify all units into five classes representing five different levels of importance. Different color tones are used to express varying importance - the deeper the color, the higher the importance (Fig. 8).

From Fig. 8, the following areas in Mentougou have higher indication of conjugate ecological restoration importance:

(1) Eastern mineral scale exploration areas. In these areas, there is a long history of mineral exploration and the destructions caused by the exploration activities are very serious. At the same time, there are abundant water resources, flat terrain, convenient traffic, advantageous position, integrated infra-

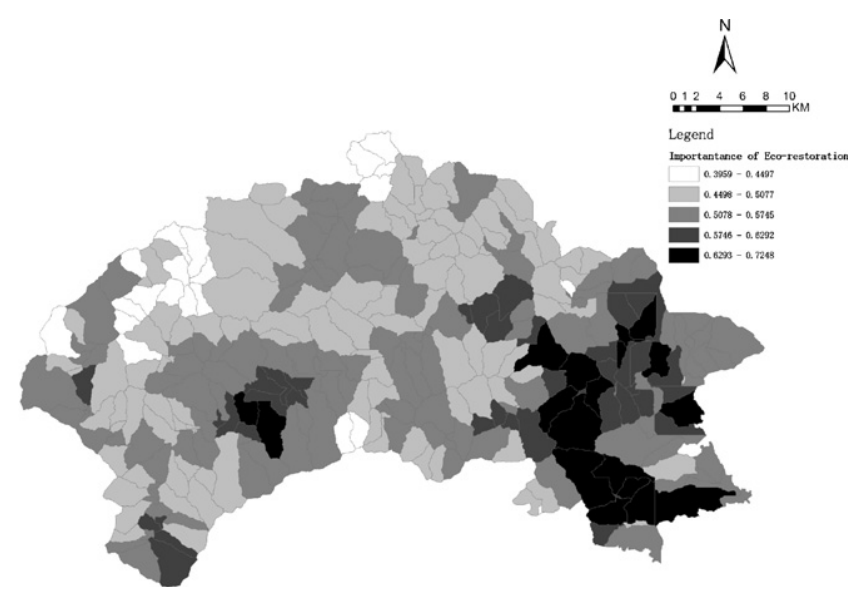

Fig. 8. Evaluation result. 


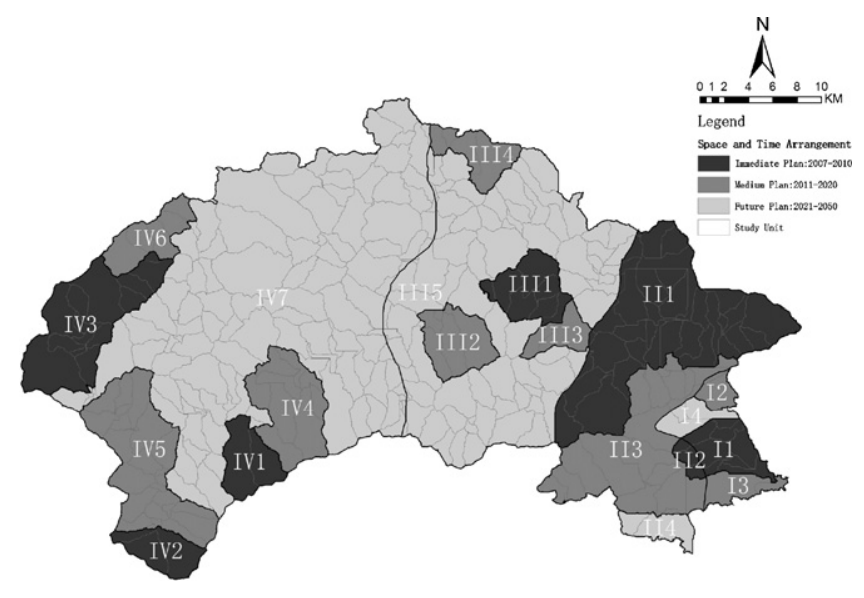

Fig. 9. Time and space arrangement of ecological restoration in Mentougou.

structures, high density of population and strong economical strength. All these reasons lead to the higher importance of ecological restoration.

(2) Regions along Yongding River and Yanchi agriculture areas in middle Mentougou. These areas have fertile soil and relatively abundant water resource. No. 109 national road passes through these areas along Yongding River. Thus, the area has natural advantages to develop ecological agriculture, which benefits the higher importance of restoration.
(3) Ecological barrier region, including Baihua Mount and Lingshan Mount. Levels of Normalized Difference Vegetation Indicator (NDVI) and elevation in this area are very high, which makes this area the western ecological barrier of Beijing; there are some ecological degradations in this area because of the unregulated tourism development in recent years. It is therefore necessary to restore them preferentially.

\subsubsection{Natural ecosystem restoration}

According to the evaluation result, considering the convenience to management and the difficulty of restoration, the natural ecosystem restoration is given a time-order plan, that is, Immediate plan: 2007-2010; Medium plan: 2011-2020; and Future plan: 2021-2050.

See the time and space arrangement in Fig. 9.

A detailed restoration plan in each lower layer region is designed according to the evaluation result, and the development plan for the restoration area is done. Considering the character of degradation and status of indicators in each region and based on field experiments, the techniques are integrated, the technique combination for each type of degradation in Mentougou is designed. The eco-restoration demonstration projects are likewise designed (Tables 3 and 4).

\subsubsection{Economical and social ecosystem restoration}

The existing industrial structure of Mentougou district will be regulated according to its functional orientation, existing condi-

Table 3

Restoration techniques for different types of degradation.

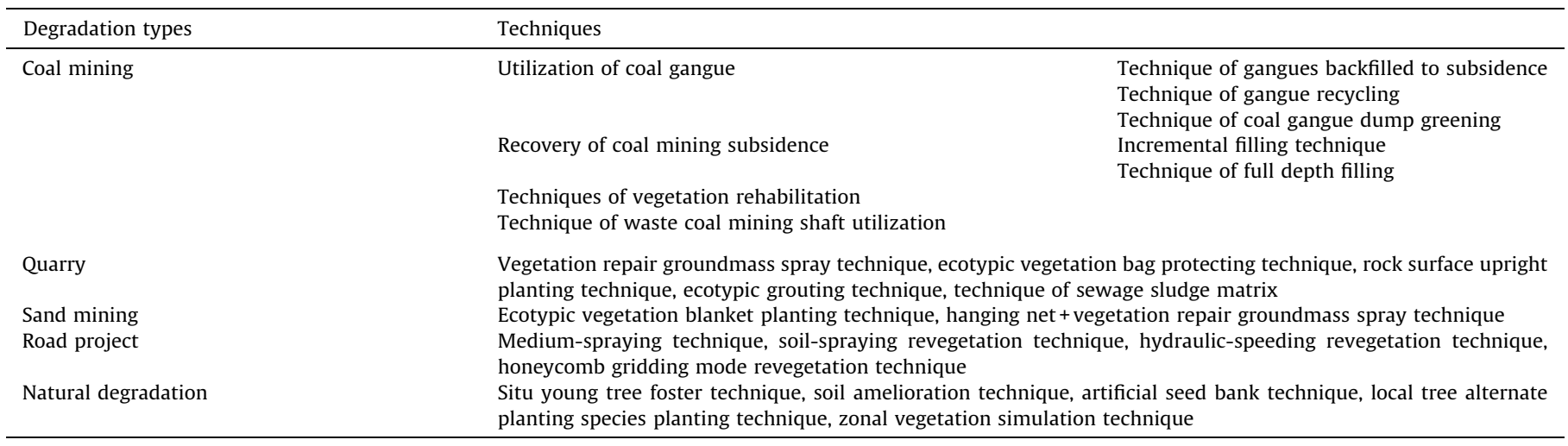

Table 4

Eco-restoration demonstration projects.

\begin{tabular}{|c|c|c|c|}
\hline Location & Project site & Type & Restoration area $\left(\mathrm{h} \mathrm{m}^{2}\right)$ \\
\hline Tanzhesi town & Nancun, Beicun, Lujiatan & Lime mining & 3.80 \\
\hline Miaofengshan town & $\begin{array}{l}\text { Da Heyu, Xiao Heyu } \\
\text { Taoyuan } \\
\text { Haungtutai }\end{array}$ & $\begin{array}{l}\text { Quarry } \\
\text { Quarry } \\
\text { Road slope }\end{array}$ & $\begin{array}{r}22.67 \\
2.67 \\
0.13\end{array}$ \\
\hline Yanchi town & $\begin{array}{l}\text { Qinyukou } \\
109 \text { national road section }\end{array}$ & $\begin{array}{l}\text { Sand excavation } \\
\text { Road slope }\end{array}$ & $\begin{array}{l}8.67 \\
0.27\end{array}$ \\
\hline Zhaitang town & $\begin{array}{l}\text { Huangchengyu } \\
\text { Qinglongjian } \\
\text { Huocun } \\
\text { Langhugou } \\
\text { Jiulongtou }\end{array}$ & $\begin{array}{l}\text { Coal mining } \\
\text { Coal mining } \\
\text { Coal mining } \\
\text { Coal mining } \\
\text { Waste coal mining shaft }\end{array}$ & $\begin{array}{r}0.67 \\
3.00 \\
1.33 \\
15.33 \\
0.07\end{array}$ \\
\hline $\begin{array}{l}\text { Qingshui town } \\
\text { Baihua Mountain } \\
\text { Wangping town } \\
\text { Longquan town }\end{array}$ & $\begin{array}{l}\text { Shang Qingshui } \\
\text { Roads to mountaintop } \\
\text { Wangping wetland } \\
\text { Zhongmensi - Zhaojiawa }\end{array}$ & $\begin{array}{l}\text { Waste coal mining shaft } \\
\text { Road slope } \\
\text { Degradation wetland } \\
\text { Bare rock }\end{array}$ & $\begin{array}{r}0.13 \\
2.53 \\
10.00 \\
0.07\end{array}$ \\
\hline
\end{tabular}


tions and present industry status. The following options are selected as the leading industries: (1) the ecological restoration industry; (2) the logistics industry of ecological products; (3) the transaction industry of ecological technology; (4) the health products and health services industry; (5) the ecological leisure and tourism industry; (6) the ecological culture and exhibition industry; (7) the consulting industry of ecological construction; (8) the industry of characteristic ecological agriculture-forestry; (9) the vein resources recovery industry.

The scientific ecological management can guarantee the efficiency of the economical and ecological restoration plan. According to the existing problems of the ecological assets management in Mentougou district, a series of related measures/policies should be made and taken, including: (1) management system, investment and financing mechanism, policy, technique research on ecological restoration and other external supporting conditions; (2) talent introduction, (3) industrial incubation mechanism, (4) assets management, and (5) management capability construction. Meanwhile, the policy of ecological compensation and the management mechanism should be made.

\subsection{Scenario analysis}

There are six drive indicators as follows: (1) the policies for ecoenvironment management, (2) the direction of industrial development, (3) the regional eco-risk, (4) the financial support from government, (5) the financial policies of market, and (6) the human resource support, which could contribute more to the positive effects of ecological restoration than the other indicators. Among them, the policies for eco-environment management and the regional eco-risk are more stable, while the direction of industrial development, the financial support from government, the financial policies of market, the human resource support are full of uncertainties. Because there is co-relationship between different scenarios, this study refined three special scenarios as follows: gradual restoration within the practical capacity (GR Scenario), forced restoration led by the government (FR Scenario), and conjugated restoration based on the theory of social-economicnatural complex ecology (CR Scenario).

Scenario 1: Gradual restoration within the practical capacity (GR Scenario)

The CR Scenario means that Mentougou district government shall implement the policies of environmental management under the current capacity of institution, policy, and planning framework.
The investment and human intelligence of Beijing and Mentougou governments shall mainly focus on the restoration of the area characterized by high eco-destruction, big eco-risk, easy restoration, and significant potential profit.

Scenario 2: Forced restoration led by the government (FR Scenario)

The FR Scenario means that Mentougou district government shall implement the strict policies of environmental management, and continues to enhance the current institution, policy, and planning framework. Meanwhile all high consumption of resources and environment unfriendly industries shall be shut down, and tourism shall be developed in some high environmental capacity area. The Beijing and Mentougou governments would put huge funds, powerful engineering techniques, and rich human intelligence into the eco-destructive area step by step.

Scenario 3: Conjugated restoration based on the theory of socialeconomic-natural complex ecology (CR Scenario)

Scenario 3 means that the Mentougou district government shall implement the strict policies of environmental management, and shall revise the current institution, policy, and planning framework to come out with introductory policies of environmental management. Meanwhile, all high consumption of resources and environment unfriendly industries shall be shut down, and ecoindustries with potential ecological development shall be developed, and ecological construction shall be carried out. The government shall attract more external funds through its policy of developing eco-restoration industries. The finances of Beijing and Mentougou governments shall be combined; intelligence groups shall be organized, including socioeconomic, science, and engineering think tanks, and local people shall be encouraged to participate in eco-restoration, then eco-restoration shall be carried out step by step.

We set five grades for every evaluation indicator; the higher the grade, the more benefits to the complex ecosystem of Mentougou. Then we grade the after-effect benefits of the following eight indicators of the three scenarios through brainstorming by experts: (1) regional eco-risk, (2) economic growth, (3) capacity of resources and environment, (4) natural eco-benefit, (5) socialeconomic benefit, (6) burden of public finance, (7) driving power of market finance, and (8) technical support. We will then carry out a comprehensive discussion on them.

Fig. 10 shows the results of the three scenarios (when the value of the indicator is bigger, the effect is more positive). Scenario 1 shows that though the financial burden on the government is

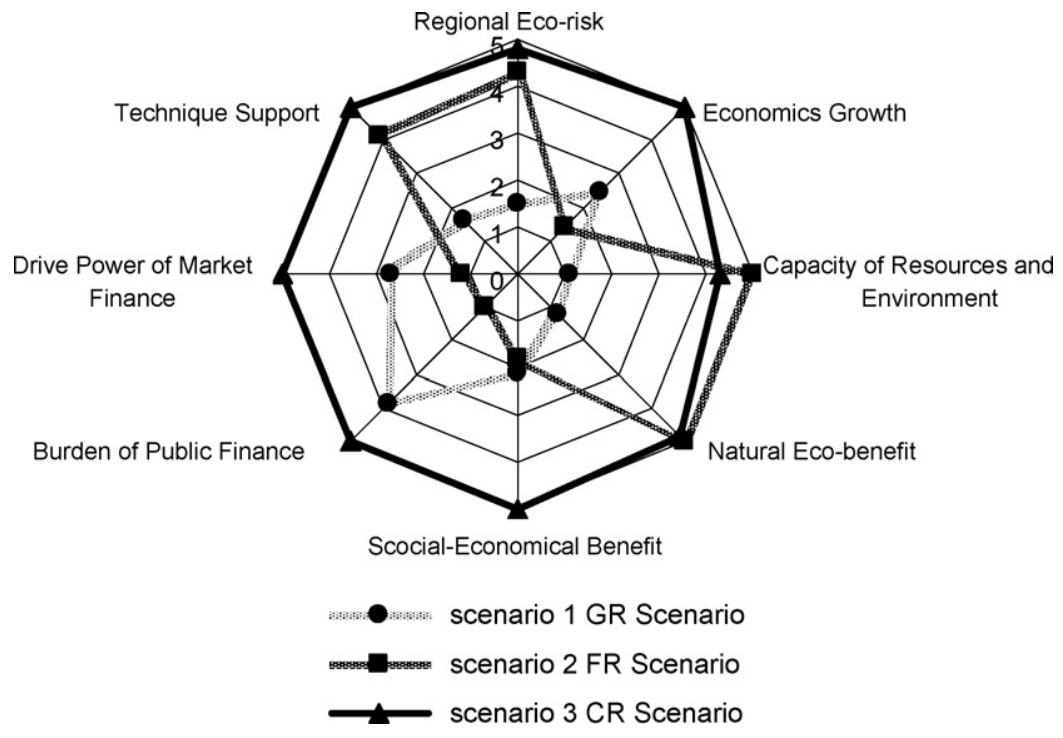

Fig. 10. Results of scenario analysis. 
small, the regional eco-risk and the resources and environment capacity have entered into a risk situation. Though the economy could develop quickly, it would stop soon. The natural eco-benefit and social-economic benefit are non-ideal. The technical support and the driving power of market finance would decrease. Scenario 2 shows that although the regional eco-risk and the resources and environment capacity could get into a good situation, they could restrict economic growth. The social-ecological benefit will be poor, and the government will face great financial burden. Scenario 3 shows that the resources and environment capacity could be maintained at a proper level with low eco-risk and high economic growth. The technical support and the drive of market finance are powerful; meanwhile, the financial burden is small, which could mean significant ecological and social benefits.

\section{Discussion}

Studies indicate that the significant characteristics of serious degradation areas are that environment pollution and economic poverty interlace, resource exhaustion and slow development conjugate, fragile ecology and low population quality go hand in hand, etc. Activities that only protect environment or only construct economic growth cannot guarantee regional ecological security. Poverty, unemployment, and underdeveloped economy are key factors that impact ecological security the most. If natural conservation is not supported by social and economical development, the tasks of conservation will be difficult to accomplish. Depredated areas must develop the circular economic which adapt to local ecological conditions while simultaneously undertaking ecological restoration, conservation, and construction.

The objectives of ecological restoration are to (1) transform, design, plan, construct, and manage invisible ecological assets, economic potential, social activities, and system relationships; (2) approach ecology from the scientific level (science and technology); (3) manage ecosystem from the system level (governments); (4) construct ecosystem from the engineering level (enterprises); (5) propagate ecology from the social level (media); (6) experience ecology from the aesthetic level (polloi); (7) strengthen and perfect the ecological plan, activate and integrate ecological assets, incubate and induce ecological industries, and promote ecological civilization; (8) demonstrate with typical examples and break through important links; (9) promote high efficiency and harmony of society and economy based on the activity of regional ecosystem services.

In this article, the author puts forward a conjugate ecological restoration plan. When evaluating natural ecosystem, social and economical factors are added into the indicator system, which benefit the implementation of ecological restoration. In the restoration plan of natural ecosystem, the study integrates restoration technologies for different types of degradation and arranges demonstration projects for them. Moreover, restoration plan of social and economic ecosystems are made simultaneously with natural ecosystem restoration plan, which embodies the system theory and will promote the sustainable development of the whole ecosystem.

The Improved Full Permutation Polygon Synthetic Indicator Method (IFPPSI) is used for data processing in this study. Compared with the original method (Wu et al., 2005), a new parameter (weight of indicator) is added into the new model, which can reflect the varying levels of importance among different indicators. Thus the improved method is more scientific than the original one.

However, when there are no standards for the upper, lower, and critical values about the indicators, it still needs experts to judge and give the values; the weights of indicators are calculated by AHP group decision process. It cannot get rid of subjective intervention in this method. In addition, restricted by the monotonicity of the sine function, the biggest weight of all indicators should not be bigger than 0.25 and the number of indicators not less than 5 . These deficiencies restrict the application range of the method.

When the historical data are abundant, Artificial Neural Network (ANN) or other nonlinear analysis methods can be applied to data fitting and comprehensive evaluation for the conjugate eco-restoration plan. Through this way, the subjective intervention can be decreased and the result would be more objective.

\section{Acknowledgements}

This research was financially supported by the National Natural Science Foundation of China (70803050), the Key Supporting Project of Ministry of Science and Technology of P. R. China (2007BAC28B04, 2008BAJ10B05; 2009BADC2B03), and the Knowledge Innovation Project of the Chinese Academy of Sciences (KZCX2-YW-324, 422).

\section{References}

Barrow, E., Timmer, D., White, S., Maginnis, S., 2002. Forest Landscape Restoration: Building Assets for People and Nature-experience from East Africa. IUCN, Cambridge, UK.

Boon, P.J., Davies, B.R., Petts, G.E., 2000. Global Perspectives on River Conservation: Science. Policy and Practice. Wiley, New York.

Cairns Jr., J., 1977. Recovery and Restoration of Damaged Ecosystems. Univ. Press of Virginia, Charlottesville.

Cairns Jr., J., 1995. Restoration ecology. In: Nierenberg, W.A. (Ed.), Encyclopedia of Environmental Biology, vol. 3. Academic Press, San Diego, pp. 223-235.

Cheng, L., Wang, R.S., Wang, Z.L., 2007. Niche assessment of China provincial socialeconomic-natural complex ecosystems in 2003. Chin. J. Appl. Ecol. 18, 17941800 (in Chinese).

Cornelia, O., Karin, J., Juergen, M., Martin, B., Volker, G., Martin, D., 2010. Long-term socio-ecological research (LTSER) for biodiversity protection - a complex systems approach for the study of dynamic human-nature interactions. Ecol. Complex. 7, 170-178.

Dolinar, N., Rudolf, M., Šraj, N., Gaberščik, A., 2010. Environmental changes affect ecosystem services of the intermittent lake cerknica. Ecol. Complex. 7, 403-409.

Gulati, R.D., Pires, L.M.D., Donk, E.V., 2008. Lake restoration studies: failures, bottlenecks and prospects of new ecotechnological measures. Limnol.-Ecol. Manage. Inland Waters 38, 233-247.

Haeckel, E., 1866. General Morphology of Organisms; General Outlines of the Science of Organic Forms Based on Mechanical Principles through the Theory of Descent as Reformed by Charles Darwin. G. Reimer, Berlin.

Hart, P.B.S., West, A.W., Kings, J.A., Watts, H.M., Howe, J.C., 1999. Land restoration management after topsoil mining and implications for restoration policy guidelines in New Zealand. Land Degrad. Dev. 10, 435-453.

Hupfer, M., Hilt, S., 2008. Lake restoration. In: Jorgensen, S.E., Fath, B.D. (Eds.), Encyclopedia of Ecology. Elsevier, Oxford, pp. 2080-2093.

Jackson, L.L., Lopoukine, D., Hillyard, D., 1995. Ecological restoration: a definition and comments. Restor. Ecol. 3, 71-75.

Jolanta, P., 2006. Restoring nature in mining areas of the Silesian Upland (Poland). Earth Surf. Proc. Land. 31, 1685-1691.

Jordan III, W.R., 1994. Sunflower forest: ecological restoration as the basis for a new environmental paradigm. In: Baldwin, A.D.J., Judith, D.L., Carl, P. (Eds.), Beyond Preservation: Restoring and Inventing Landscape. University of Minnesota Press, Minneapolis, pp. 17-34.

Lamd, D., 1994. Reforestation of degraded tropical forest lands in the Asia-Pacific region. J. Trop. For. Sci. 7, 1-7.

Li, F., Liu, X.S., Hu, D., Wang, R.S., 2007. Evaluation method and index system of ecocity development: a case study in Dafeng City of Jiangsu Province, China. Chin. J. Appl. Ecol. 18, 2006-2012 (in Chinese).

Li, G., Wang, B.T., 2007. Discussion of a method on spatial planning of regional ecological restoration. Res. Soil Water Conserv. 14, 285-288 (in Chinese).

Ma, S.J., Wang, R.S., 1984. Social-economic-natural complex ecosystem. Acta Ecol. Sin. 4, 1-9 (in Chinese).

Maginnis, S., Jackson, W., 2002. Restoring forest landscapes. ITTO Trop. Forest Update 12, 9-11.

Majer, J.D., Brennam, K.C.E., Moir, M.L., 2007. Invertebrates and the restoration of a forest ecosystem: 30 years of research following Bauxite Mining in western Australia. Restor. Ecol. 15, s104-s115.

Mitchell, A.P., 2008. The nature of urban soils and their role in ecological restoration in cities. Restor. Ecol. 16, 642-649.

Navarro, F.B., Ripoll, M.A., Jimenez, M.N., Simon, E.D., Valle, F., 2006. Vegetation response to conditions caused by different soil-preparation techniques applied to afforestation in semiarid abandoned farmland. Land Degrad. Dev. 17, 7387.

Patten, B.C., 2010. Natural ecosystem design and control imperatives for sustainable ecosystem services. Ecol. Complex. 7, 282-291. 
Peng, S.L., 2003. Study and Application of Restoration Ecology in Tropical and Subtropical China. Science Press, Beijing (in Chinese).

Poff, N.L., Allan, J.D., Bain, M.B., 1997. The natural flow regime-a paradigm for river conservation and restoration. Bioscience 47, 769-784.

Rapport, D.J., Costanza, R., McMichael, A.J., 1998. Assessing ecosystem health. Trends Ecol. Evol. 13, 397-402.

Ravindran, K.C., Venkatesan, K., Balakrishnan, V., Chellappan, K.P., Balasubramanian, T., 2007. Restoration of saline land by halophytes for Indian soils. Soil Biol. Biochem. 39, 2661-2664.

Ren, H., Wu, J.G., Peng, S.L., 2000. Measure and monitoring of ecosystem health. Trop. Geogr. 20, 310-316 (in Chinese).

Sagehashi, M., Sakoda, A., Suzuki, M., 2001. A mathematical model of a shallow and eutrophic lake (the Keszthely Basin, Lake Balaton) and simulation of restorative manipulations. Water Res. 35, 1675-1686.

Selby, P., 2000. From cropland to wetland to classroom. Land Water 44, 55-57.

Sparks, R.E., 2001. Wetland restoration, flood pulsing, and disturbance dynamics. Restor. Ecol. 9, 112-113.

Tennant, D.L., 1976. Instream flow regimens for fish, wildlife, recreation and related environmental resources. Fisheries 1, 6-10.
Verhoeven, J.T.A., Soons, M.B., Janssen, R., Omtzigt, N., 2008. An operational landscape unit approach for identifying key landscape connections in wetland restoration. J. Appl. Ecol. 45, 1496-1503.

Wang, R.S., 1988. High Efficiency and Harmonization-Principles and Methods of City Ecology Regulation. Hu'nan Education Press, Changsha, Hunan (in Chinese)

Wang, S.Y., Bian, X.M., 2007. Comprehensive evaluation of ecological economic system in Funing county of Jiangsu province. Chin. J. Appl. Ecol. 26, 239-244 (in Chinese).

Willems, J.H., 2001. Problems, approaches, and results in restoration of Dutch calcareous grassland during the last 30 years. Restor. Ecol. 9, 147-154.

Wu, Q., Wang, R.S., Li, H.Q., Xu, X.B., 2005. The indices and the evaluation method of eco-city. Acta Ecol. Sin. 25, 2090-2095 (in Chinese).

Zhou, Q.X., Wei, S.H., Diao, C.Y., 2007. Basic principles and researching progresses in ecological remediation of contaminated soils. J. Agro-Environ. Sci. 26, 419-424 (in Chinese).

Zurlini, G., Riitters, K., Zaccarelli, N., Petrosillo, I., Jones, K.B., Rossi, L., 2006. Disturbance patterns in a socio-ecological system at multiple scales. Ecol. Complex. 3, 119-128. 